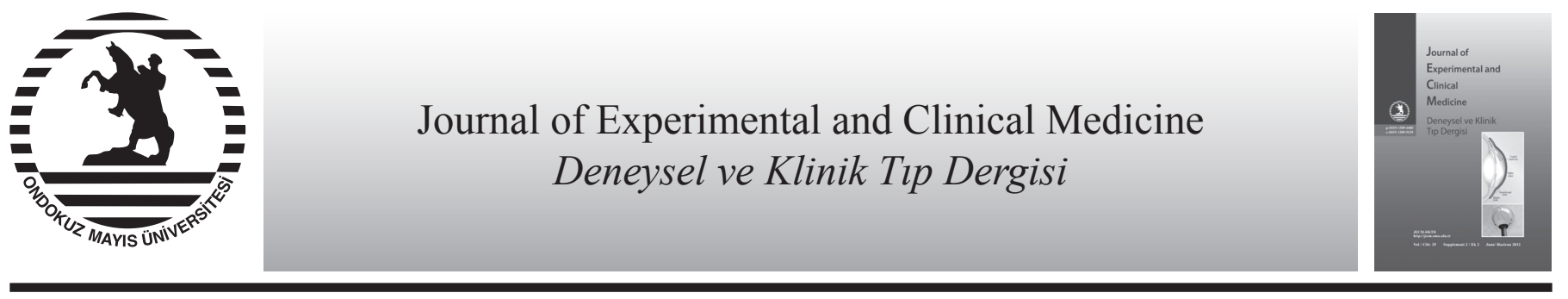

Derleme / Review

doi: $10.5835 /$ jecm.omu.29.s2.004

\title{
Glokomda görme alanı defektleri
}

Visual field defects in glaucoma

\section{Nurşen Aritürk}

Ondokuz Mayıs Üniversitesi, Tıp Fakültesi, Göz Hastalıkları Anabilim Dalı, Samsun, Türkiye

\begin{tabular}{|c|c|}
\hline \multicolumn{2}{|c|}{ MAKALE BİLGÍLERİ } \\
\hline \multicolumn{2}{|c|}{ Makale geçmişi } \\
\hline Geliş & $30 / 06 / 2011$ \\
\hline Kabul & 05 / 07 / 2011 \\
\hline
\end{tabular}

\section{Yazışma Adresi:}

Nurşen Arıtürk

Ondokuz Mayıs Üniversitesi, Tıp Fakültesi, Göz Hastalıkları Anabilim Dalı, Samsun, Türkiye

E-posta: ariturknursen@gmail.com

\section{Anahtar Kelimeler:}

Glokom

Görme Alanı

Optik sinir

Perimetre

Retinal sinir lifi tabakası

Görme alanı defekti

\section{Keywords:}

Glaucoma

Visual field

Optic nerve

Perimeter

Retinal nerve fibre layer

Visual field defect

\section{ÖZET}

Glokom, ilerleyici, geri dönüşümü olmayan, optik disk ve retina sinir lifi tabakasındaki yapısal değişiklikler ve görme alanındaki fonksiyonel kayıplarla karakterize, birçok faktorün sorumlu olduğu bir hastalıklar grubudur. Oftalmologların birincil amacı, glokom tanısı ve takibinde sinir lifi kayıplarını belirlemek, kayıp gelişimini önlemek ve progresyonu durdurmaktır. Teşhis ve takipte kullanılan geleneksel yöntemler, göz içi basınç ölçümü, optik sinir başının subjektif incelenmesi ve görme alanı testidir. Göz içi basınç ölçümü diürnal varyasyon göstermesi, kişisel farklılıkların olması ve risk faktörlerinden sadece biri olması nedeniyle tek başına tanı koymada yeterli değildir. Optik sinir başının subjektif incelenmesi, gözlemci ve gözlemciler arası farklı değerlendirmeler ve kişisel farklılıklar olabilmesi güvenilirliğini azaltmaktadır. Görme alanı testi ise, glokomun klinik olarak takibinde vazgeçilmez değerlendirme yöntemlerinden biridir. Subjektif bir test olması, kısa ve uzun süreli değişikliklerin olması teste güvenilirliği azaltsa bile halen günümüzde tanı ve takipte, klinik olarak görme fonksiyonunu belirlemede vazgeçilmez altın standart yöntemdir. Bu makalede, glokomda görülen görme alanı kayıp tipleri, literatür verileri ışı̆̆ında tartışılmıştır. J. Exp. Clin. Med., 2012; 29:S66-S-S74

\begin{abstract}
Glaucoma, is a group of diseases caused by several factors characterized by progressive, irreversible structural changes at the optic disc and retinal nerve fiber layer, and the functional loss in the visual field. The primary purpose of the ophthalmologist is to determine the level of the loss of retinal nerve fibers during the glaucoma diagnosis and the followup; and to prevent and to stop the progression of nevre fiber loss. Conventional methods used for glaucoma diagnosis and follow-up are intraocular pressure measurements, subjective examination of the optic nerve head and visual field test. Intraocular pressure measurement is not enough alone for glaucoma diagnosis, because it shows diurnal variation, individual differences and it is only one of several risk factors. Subjective evaluation of the optic nerve head, the interobserver variability of the assessment and individual differences of optic disc size and type should reduce its reliability. The visual field test is one of the indispensable assessment methods. For today, it is still the gold standard method for the diagnosis and the follow-up of glaucoma, and to determine clinically the visual function. Even if it is a subjective test,and the short-and long-term fluctuations should decrease the reliability of the test.In this article, the types of visual field loss in glaucoma are discussed in the light of the current literature.

J. Exp. Clin. Med., 2012; 29:S66-S-S74
\end{abstract}

\section{Giriş}

Glokomatöz görme alanı kayıpları hasta için, hastalığın en önemli semptomudur. Glokomatöz görme alanı kaybı retina ganglion hücreleri ile lamina kribrosa arasındaki bölüm- lerin hasarına bağlı olarak gelişir. Genellikle sinir lifi demet defekti şeklindedir. Glokomda görme alanı kayıpları tipik olarak fiksasyon alanından uzaktır ve görme keskinliği son evreye kadar korunmasına rağmen, fiksasyon alanına yakın 
dens bir alan defekti santral görme kaybı için risk oluşturabilir. Özellikle ileri evre glokomlarda glokomatöz alan kayıpları yaşam kalitesiyle çok yakından ilişkilidir. Hiçbir psikofiziksel test (görme keskinliği, renkli görme, kontrast sensitivite gibi), glokoma bağlı görme hasarını perimetri ile elde edilen sensitive kayıpları gibi gösteremez. Perimetrik test sonuçları glokom için sıklıkla spesifiktir. Fakat görme alanı defektlerinin hiçbiri \%100 glokom için spesifik değildir..

Görme alanı (GA), karanlık denizinde kıyıları sığ, merkezine doğru yükselen bir adacık olarak tanımlanmaktadır (Traquair'in görme alanı adası). Bu adacığın en tepe noktası retinal duyarlılığın en yüksek olduğu foveaya karşılık gelir ve bu adacık perifere doğru giderek azalan duyarlılık eğimine sahip bir tepe görünümündedir. Glokomda ilk kez görme alanında parasantral defekt ve görme alanında darlık varlığını Graefe bildirmiştir. Daha sonra Förster, glokomda periferal görme alanı değişikliklerini, Bjerrum erken santral görme alanı defektlerini tanımlamıştır (Mikelberg ve Drance1996). 1945 de Goldmann perimetrisinin standartize edilmesi, statik perimetrelerin uygulamaya girmesi ile glokomda izole parasantral defektler, santral veya periferik nasal step gibi en erken tesbit edilebilen lokalize alan defektleri tanımlanmıştır (Drance, 1969; Armaly, 1972; Phelps ve ark., 1984).

\section{Görme alanını değerlendirmede kullanılan terimler}

Görme alanı defekti, optik sinirin anatomik hasarının fonksiyonel karşılığıdır ve glokomun belirleyici özelliğidir. Görme alanı defektlerinin tanımlamasını yaparken kullanılan bazı terimler mevcuttur. Bunların açıklanması konunun daha iyi anlaşılmasını sağlayacaktır:

\section{a-Görme alanı}

Gözün belli bir noktaya fikse olduğunda çevrede algılayabildiği alanın tümüdür. Genişliği derece $\left(^{\circ}\right)$, derinliği duyarlılık (dB) olarak ifade edilir. Normal bir gözde görme alanı genişliği üst ve nasalde $60^{\circ}$, altta $70-75^{\circ}$ ve temporalde 100 $110^{\circ}$ dir (Anderson ve Patella,1999). Görme alanı testinde retinanın ayna hayali görünümü mevcuttur yani nasal retina GA'nın temporalini, temporal retina GA nın nasalini, üst retinal bölge GA'nın alt yarısını, üst retinal alan, GA'nın alt yarısını oluşturur (Şek. 1). Duyarlılık 32-34 dB dir.

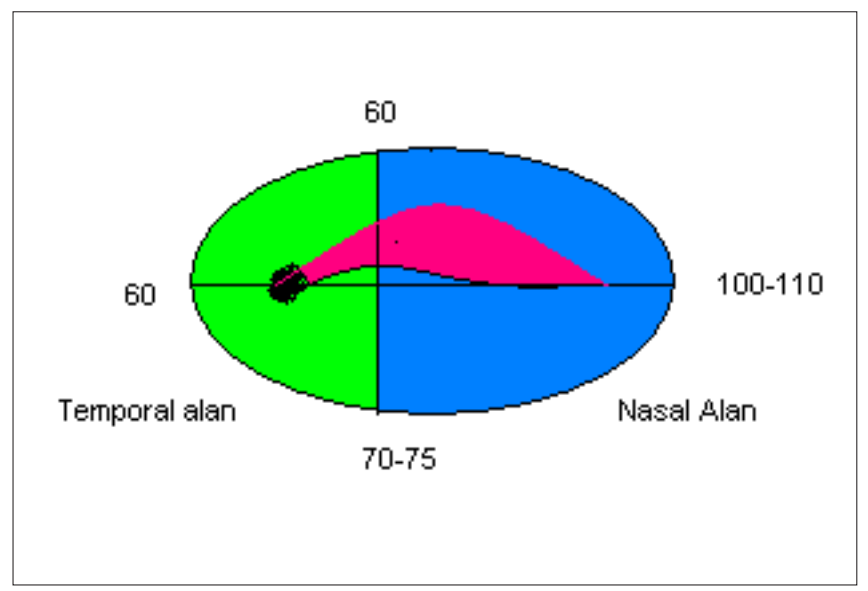

Şek. 1. Normal bir gözde görme alanı genişliği ve üst yarıdaki Bjerrium alanının şematik resmi ve GA testinde ayna hayali görünümü (nasal retina= temporal GA, temporal retina=nasal GA)

\section{b-İzopter kavramı}

Görme alanında belli şiddette ve büyüklükte bir uyaranı görebilen noktaların birleştirilmesi ile ortaya çıkan eşik sınırına verilen addır. Goldmann Perimetresi ile yapılan değerlendirmede kullanılır.

\section{c-Summasyon}

Küçük bir uyaranın görülmediği bir alanda, aynı şiddette fakat daha büyük uyaranın görülebilmesine denir. Küçük uyaranın ortaya çıkaramadığı fotokimyasal reaksiyonun, birbiri ile ilişkili daha fazla sayıda fotoreseptörün uyarılması ile ortaya çıkması mümkün olabilmektedir. İki tipi vardır: Spatial summation (Uzaysal birikme): Uyaran süresi sabit, uyaran büyüklüğünün değişken olduğu durum, Temporal summation: Uyaran büyüklüğü aynı, süre değişkendir. Belli bir süre gösterilip görülmeyen uyaran, daha uzun süre gösterildiğinde fark edilebilir.

\section{d-Depresyon}

Retinal duyarlılık azalmasıdır.

\section{e-Skotom}

Çevresi daha yüksek retinal duyarlılığa sahip retinal depresyon alanıdır. Normal görme alanı tepeciğinden klinik ve istatiksel olarak ayrılma görme alanı defektini oluşturur. Görme alanı defektleri lokalize veya genel depresyon şeklinde olabilir. Genel depresyon: tüm görme alanını kapsayan retinal duyarlılık azalmasıdır. Pupil çapı, katarakt gibi ortam opasiteleri, refraksiyon kusurları ve glokom neden olabilir. Lokalize defekt: Görme alanı içinde belli bir bölgede ortaya çıkan retinal duyarlılık azalmasıdır. Bu bölgeler normalden düşük şiddette uyaranla uyarıldığında yanıt alınabilirse relatif skotom, normalden daha yüksek şiddette uyaranla bile yanıt alınamazsa absolü skotom olarak ifade edilir. Glokomda görülen karakteristik alan defekti şeklidir. Otomatik perimetrelerde, skotomları ortaya çıkarmak için çok sayıda stimulus lokalizasyonu, stimulus büyüklükleri ve 1şık yoğunluğu vardır.

\section{f-Fiksasyon noktası}

Görme alanı içinde fovea santraline uyan kısımdır. Merkezi görme alanı, fiksasyon noktası içindeki $30^{\circ}$ lik, santral görme alanı fiksasyon noktası içindeki $10^{\circ}$ lik alandır.

\section{g- Bjerrium alanı}

1889'da ilk kez Bjerrium tarafından tanımlanmıştır. Fiksasyon noktasının nasalinden kör noktaya uzanan, fiksasyonun alt ve üstünde ark yapan ve horizontal meridyende sonlanan görme alanıdır. Fiksasyon noktasının $10^{\circ}-20^{\circ}$ temporali ile $2-25^{\circ}$ nasali arasında kalan bölümdür.

$\mathrm{Bu}$ alan retinadaki arkuat sinir liflerinin dizilimine uyar

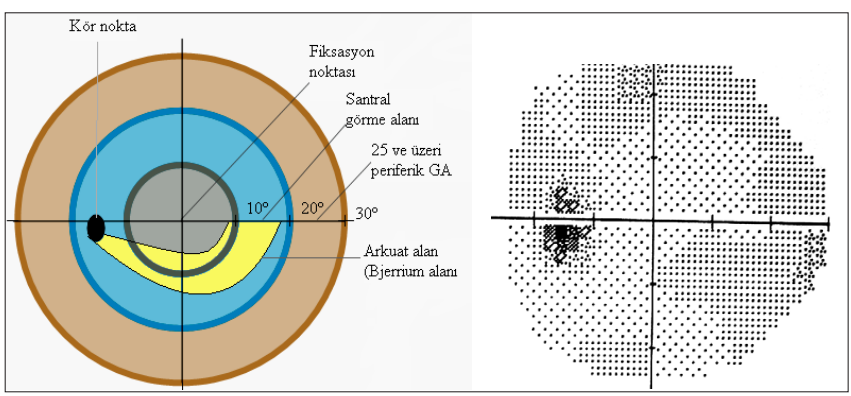

Şek. 2. Şematik ve Humprey 30-2 eşik testinde normal bir gözde gri skalada görme alanı görünümü 
ve glokom hasarına en duyarlı bölümdür (Şek. 2).

\section{h- Kör nokta}

Retina hakkında görsel bilgi veren sinir lifleri foveanın yaklaşık 10-15 derece nasalinde bir araya gelirler. Bu bölge optik sinir başına karşılık gelir ve fotoreseptör içermez, normal görme alanı sınırları içinde derin depresyon oluşturur ki; bu bölgeye kör nokta denir. Kör nokta daima fiksasyon noktasının temporalinde yer alır.

\section{i- Periferik alan \\ $25^{\circ}$ ve üzeri olan bölgedir.}

\section{j-Fluktuasyon}

Görme alanı ölçümlerindeki değişikliklerdir. Kısa veya uzun süreli olabilir. Kısa süreli fluktüasyon, test sırasında hasta yanıtındaki değişikliklerdir. Genellikle hastanın dikkat kaybından kaynaklanır, hep aynı noktada ise glokomun erken bulgusu olabilir. Uzun süreli fluktüasyon ise takipler sırasında yapılan aynı göze ait görme alanları arasındaki değişikliklerdir.

\section{Glokomda görme alanı değerlendirmesi}

Normal ve anormal görme alanı çok iyi tanımlanmıştır. Kişisel farklılıklar oldukça azdır ve yaşın etkisi iyi bilinmektedir. Yaş arttıkça duyarlılıkda lineer bir azalma ( 0,5 veya $1 \mathrm{~dB} /$ dekad) görülmektedir. Ayrıca yaş arttıkça uzun süreli fluktuasyonlar da artmaktadır. Genç bir hastada normal santral görme alanında ortalama sensitivite değerlerinin standart sapması 1-2 dB iken, 60 yaş ve üzerinde santralde bu değer iki katına, 30 derecelik alan dışında $10 \mathrm{~dB}$ e çıkmaktadır (Heijl A, Bengtsson, 1996). Santral görme alanı hassasiyeti normalde 29-37 dB arasında değişir. Santralde $5 \mathrm{~dB}$, periferde 10 dB'e kadar sensitivite azalması normal kabul edilir. Görme alanında $1^{\circ}$ eksentrite, $0,3 \mathrm{~dB}$ azalmaya neden olmaktadır (Heijl ve ark.,1987).

\section{Glokom hastalarında görme alanı testinin kullanım} amaçları

1-Glokoma bağlı hasarı göstermek ve sensitivite kaybını erken dönemde belirlemek ana amaçtır. Özellikle göziçi basıncı (GİB) yüksek olgularda "Glokom ve Oküler Hipertansiyon" ayırımında gerekli testlerden biridir. Ayrıca normal tansiyonlu glokomlarda glokomatöz hasarın dokümentasyonunda önemlidir. Karakteristik alan kayıplarının varlığı, görülebilir optik disk hasarı ve retinal sinir lifi kayıpları varlığında bile en geçerli tanı bulgusudur. Optik disk topografik bulguları normal kişilerde kişisel farklılıklar gösterebilir ve büyük veya küçük optik disk varlığında glokomatöz değişikliği ayırt etmek zor olabilir. Bu durumlarda görme alanı defekt varlığ1 tanı koydurucu en önemli tanı kriteri olacaktır (Heijl 2000). Ayrıca optik disk topografik imaj analizleri pahalı ekipman gerektirmektedir.

2- Ayırıcı tanı için sensitivite kaybının karakteristik paternini belirlemektir. Glokom için tipik görme alanı defektleri oluşsa bile hiçbir defekt glokom için \%100 spesifik değildir.

3-Glokom takibinde kullanılır. Progresyon, stabilite veya düzelme gibi görme alanı kayıpları için, hastayı izlemede yardımcıdır. Glokomun seyri sırasında erken ve geç dönemde sensitivite ve alan kayıpları oluşmaktadır. Glokomatöz görme alanı kayıpları tipik olarak santralde, Bijerium alanında, nasalde daha ağırlıklı olarak görme alanının üst yarısında başlar
(Gramer ve ark., 1982). Erken dönemdeki kayıplar lokalizedir, yani görme tepesinin biçiminde değişiklere yol açar. Çoğunlukla arkuat alanda yer alır ve defekt alanı belirginleştikçe çoğunlukla temporal horizontal alana doğru ilerler.

\section{Görme alanını değerlendirmede izlenen yol}

Görme alanını incelerken bizi sonuca götüren küçük, fakat önemli ayrıntılar vardır. Bu ayrıntıların, sistematik yapılan bir değerlendirmede gözden kaçırılması zordur. GA değerlendirmesi 5 basamakda yapılır:

1.basamak: Görme alanı çıktısı önümüze, sağ göze ait olanı sağ tarafa, sol göze ait olan sol tarafimızda olacak şekilde konulur.

2.basamak: Görme alanı sonuçları normal limitlerin d1şında ise, tek gözde mi, iki gözde mi ona bakılır. Tek gözde ise, kiyazmaya kadar olan bölümde, yani optik sinir, retina veya optik sinir başında patoloji var demektir. İki gözde alan defekti varsa, kiyazma ve/veya retrokiyazmal, yada iki gözde patoloji var demektir.

3.basamak: İki gözde varsa, alan defektinin lokalizasyonu (alt, üst binasal, bitemporal v.b), değerlendirilir. Bitemporal ise kiyazmal patoloji, binazal ise daha çok optik sinir hastalıkları (glokom, optik nöropati veya anterior sikemik optik nöropati) ve retina hastalıkları düşünülür.

4.basamak: Defektin şekline bakılır. Diffüz, yaygın veya lokalize olup olmadığı incelenir.

5.basamak: Görme alanı ile diğer klinik bulguların retina, optik disk, retina sinir lifi tabakası (RSLT) ve nöroradyolojik görüntüleme bulguları gibi, ilişkisi araştırılır.

\section{Glokomatöz alan defektleri}

Glokomda yapısal ve fonksiyonel hasar retinal ganglion hücrelerindeki fizyopatolojik değişiklikler ve ganglion hücresi ölümünün sonucudur. Görme alanı defekti optik sinirin anatomik hasarının fonksiyonel karşılığıdır ve bu glokomun belirleyici bulgusudur. Retinal sinir liflerinin veya retinal ganglion hücre aksonlarının retina yüzeyindeki dağılımı ve optik diske uzanım şekli görme alanı defekt şeklini belirlemektedir. Retinal ganglion hücre sinir lifleri veya aksonları optik sinir başına 3 belirgin grup şeklinde girer (Şek. 3). Birinci grup papillamaküler liflerdir.

Retina ganglion hücre liflerinin \%60-70'i “papillamaküler bundle" da yer alır ve mum alevi şeklinde olup optik sinirin temporalinden giriş yapar ve santral görme alanını oluşturur.

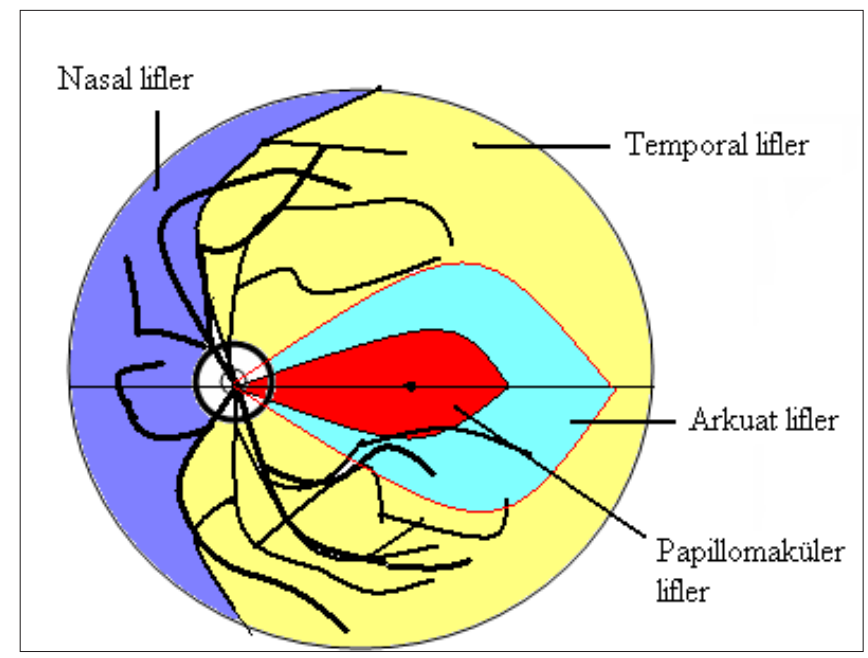

Şek. 3. Retinal sinir liflerinin dağılımı 
İkinci grup, periferal nasal retinadaki ganglion hücre lifleridir. Radial olarak seyreder ve optik diskin nasalinde yer alır ve temporal görme alanını oluşturur. Üçüncü grup sinir lifleri, optik diskin alt ve üst bölgelerinde yer alan papillamaküler lif demetlerinin üst ve altında arkuat patern oluşturan liflerdir. Temporal retinada makuladan optik diske uzanan alt ve üst liflerin birbirinden ayrılmasina yol açan horizontal raphe vardır. "Horizontal raphe" temporal retinayı ikiye bölen alt ve üst yarıdaki liflerin papillaya uzanış şekillerinin oluşturduğu fizyolojik hayali meridyendir. Ganglion hücre aksonları üsttekiler üstte daima horizontal raphe boyunca uzanır ve optik diskin üst polünden, alttakiler altta aynı şekilde uzanır ve alt polden giriş yapar. Arkuat sinir lifi demetleri optik sinir başının üst ve alt bölgesinden girerler ve glokomda hasara en duyarlı liflerdir.

Glokomatöz alan defektleri tipik olarak santralde, Bjerrium alanında, nasalde ve daha çok üst yarıda oluşur (Phelps ve ark., 1984). Horizontal meridyeni aşmaz ve retina sinir lifi (RSL) demet defektinin ayna hayali olarak yani alt yarı RSL defekti, görme alanında üst yarıda görülür. Genellikle fiksasyon noktasından uzaktır. Çoğunlukla lokalize defektlerdir. Defekt alanı genişledikçe temporal yarı alana uzanır.

Glokom hastalarının çoğunluğunda alan kayıpları varlığında klinik olarak tanımlanabilir disk değişiklikleri de mevcuttur. Quigley ve ark., (2003) görme alanı kayıpları ile birlikte optik sinir başı değişikliğinin korele olduğunu tesbit etmişlerdir. Ayrıca görme alanı kaybı oluşmadan sinir lifi kaybı olduğu, daha fazla kayıp olmasına rağmen görme alanında kayıp olmayabileceğini bildirmişlerdir. Retinanın santralinde 30 derecelik alanda ganglion hücrelerinin $\% 20$ kaybı retinada $5 \mathrm{~dB}$ duyarlılık kaybı, \%40 hücre kayb1 $10 \mathrm{~dB}$ duyarlılık kaybı oluşturduğu saptanmıştır (Quigley ve ark., 1989). Optik sinir başındaki "cupping" görünümü de alan kayıp tipleri hakkında bilgi verebilir. Yaygın veya fokal nöral rimde kayıplar olabilir. Özellikle üst ve alt poldeki kayıplar, görme alanında arkuat alan içinde defekt gelişimini gösterir. Nadiren de optik diskde solukluk gelişmeden alan kayıpları olabilir. Genel olarak optik diskte lokalize nöral rim değişiklikleri görme alanında lokalize, optik diskde genel solukluk, görme alanında genel depresyon şeklinde görülür (Drance ve ark., 1986). Yapılan randomize klinik çalışmalardan oküler hipertansiyon (OHT) çalışmasında, OHT olgularında GA değişikliği görüldüğünde, olguların \%19'unda optik sinir başında (OSB) değişiklik, \%49'unda retinal sinir lifi tabakasında kayıp tesbit edilmiştir (Gordon ve ark., 2002). Ayrıca, her 100 ganglion hücre kaybına karşl1ık 0,2-0,4 dB eşik değer kaybı, statik perimetrilerde $6 \mathrm{~dB}$ lik kayıp için \%20-50 oranında ganglion hücre kaybı oluştuğu, arada doğrusal bir ilişki bulunmadığı tesbit edilmiştir (Quigley ve ark., 1989).

Her bir optik sinir hastalı̆g horizontal meridyende görülen herhangi bir görme alanı defektine yol açabilir. Alan defeklerinin ayırıcı tanısında eşlik eden diğger klinik bulgular GİB, optik sinir görünümü, ailede glokom öyküsü ve diğer risk faktörleri araştırılmalıdır.

\subsection{Glokomda görme alanı kayıplarının sınıflaması}

Glokomda görme alanı kayıpları genellikle periferden başlar ve hastalığın son evresine kadar santral görme korunur. $\mathrm{Bu}$ nedenle hasta görmediğinin farkına çok geç varır. Genel olarak alan kayıpları 5 başlık altında incelenir:

\subsubsection{Periferal kayıplar}

Görme alanın periferal sınırları boyunca (Periferal nasal step, vertikal step ve temporal sektör defekti şeklinde) yer alır ve sıklıkla santral arkuat alan içinde yer alan skotomlar ile ilişkilidir. Bazı hastalarda erken glokomatöz alan kaybı olarak periferal defektler tek başına görülebilir.

Genellikle otomatik statik perimetrilerde 24-30 derecelik alan değerlendirilir, periferde oluşabilecek defektleri atlamak bu durumda mümkündür. Fakat periferal alan defektleri, genellikle nasal step şeklinde \%3-11 inde tesbit edilir (Balon ve ark., 1992).

\subsubsection{Lokalize sinir lifi tabakası kayıpları}

En önemli erken glokom defektleridir (Şek. 4). Birkaç tipi vardır: 1-Arkuat defektler: Arkuat skotom kör noktadan başlar, fiksasyonun alt ve üstünden horizontal raphe boyunca ark şeklinde uzanır ve arkuat retinal sinir liflerindeki hasara karşıllk gelir. Periferde santralden daha geniştir. Arkuat alanın oldukça nasalinde horizontal meridyen boyunca fiksasyonun 1 derece içinden, nasale doğru 10-20 derece uzanır (Harrington, 1965). Siedel skotom: Kör noktaya yakın erken dönem parasantral skotom, küçük ark şeklinde kör noktayla birleşebilir. Buna "siedel skotomu" denir. 2- Nasal basamak (nasal step): Hasara uğrayan lifler horizontal çizgi boyunca yer alan hücrelerden kaynaklanan ise, görme alanındaki defekt de orta hatta olacaktır. Genellikle üst kadranda horizontal orta hatta basamak şeklinde görülür. İnferior nasal step pek sık değildir. Nasal step santralde veya periferde olabilir.

Akut veya erken kronik açı kapanması glokomunda genellikle görülür (Lau ve ark., 2003). Nasal defekt: Nasal step tek yarı alanda kalmayıp diğer yarı alanı da tutar. Vertikal

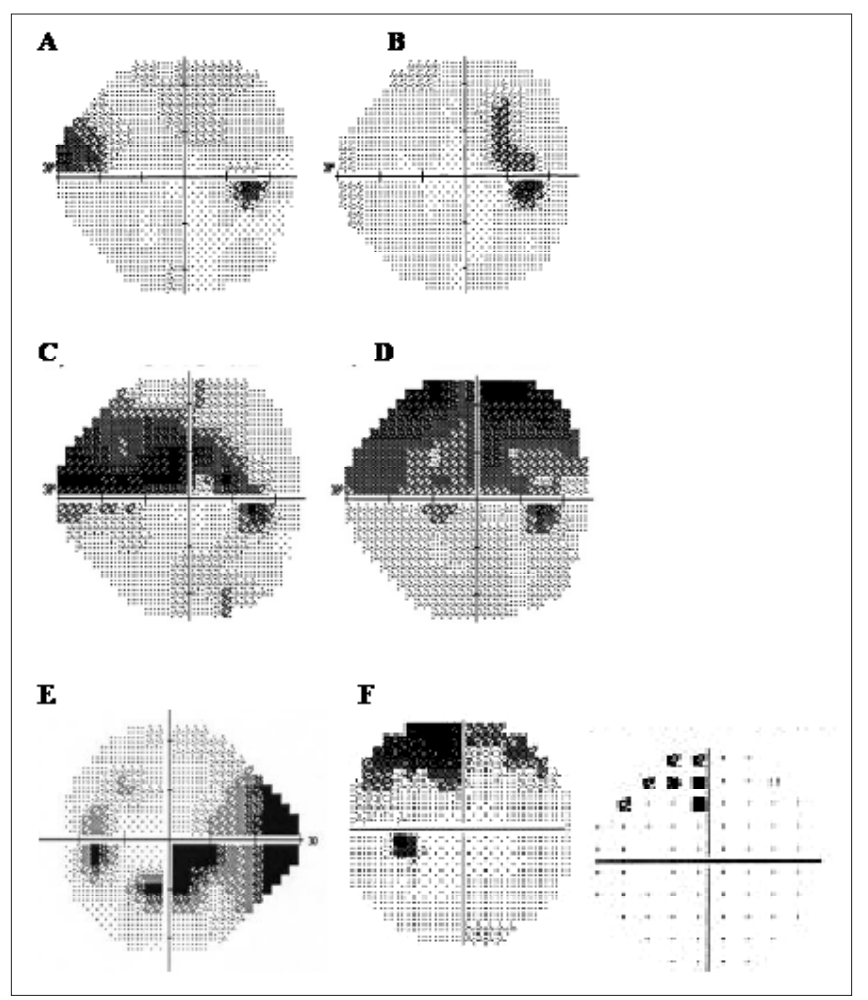

Şek. 4. Humprey 30-2 Santral eşik testinde lokalize glokomatöz görme alanı defektleri: A-Nasal basamak (step), B-Siedel Skotomu, C-Arkuat defect, D-Yarı alan defekti, E-Nasal defektve parasantral skotom , F-Vertikal basamak (step) (Gri skala ve patern deviasyon haritas1) 
step: Vertikal orta hat boyunca genelde nasal yarıda görülen alan defektidir. Pek sık görülmez. Vakaların \%20 sinde oluşur, mekanizması tam olarak bilinmemektedir. Vertikal hat boyunca sinir lifi aksonlarınındaki ayrılmadan olabileceği belirtilmektedir (Lynn, 1975). Bu tip defektlerin nörolojik lezyonlardan ayrımının yapılması gerekmektedir. Hemifield defekt: Üst veya alt yarı alanda görülen alan kayıplarıdır.

\subsubsection{Lokalize ve diffüz kombine görme alanı kayı-} lari

Lokalize kayıp ile birlikte diffüz kaybın olması glokom için karakteristik bir bulgudur. Diffüz kayıplar, ortam opasiteleri olduğunda, yaşlılarda katarakt varlığında sık görülür, glokomdan ayırt edilmesi gerekir. Erken glokom bulgusu olarak, jeneralize kontraksiyon, kör nokta büyümesi ve gece görmede azalma olabilir.

\subsubsection{Diffüz ve santral depresyon}

Santral kayıplar glokomda tüm liflerin hasara uğradığı son evre glokomda görülür. Diffüz olarak sinir liflerinin etkilenmesi ile santralde genel bir depresyon olabilir. Çok nadir de olsa, santral görmede erken dönemde kayıp olabilir (Lachenmayer ve ark., 1992). Makula hastalıklarının ekarte edilmesi gerekir. Konsatrik daralma: Jeneralize depresyon ile birlikte retinanın spesifik bölgelerinde görme alanında konsatrik daralmalar olabilir (Şek. 5). Genellikle isopter kontraksiyonu olarak ifade edilir, daha çok nasal alanda görülür ve bir erken glokomatöz alan defekti olabilir.

\subsubsection{Temporal sektör defekti}

Kör noktanın temporalinde sektör şeklindeki defektlerdir ve nasal retinal liflerin etkilenmesi ile oluşur. Superior nasal diskin etkilenmesi ile lokalize depresyon veya skotom şeklinde altda ve temporalde kör noktaya doğru ilerlemiş olarak görülür. Daha geniş alan etkilenmiş ise "wedge" şeklinde alan

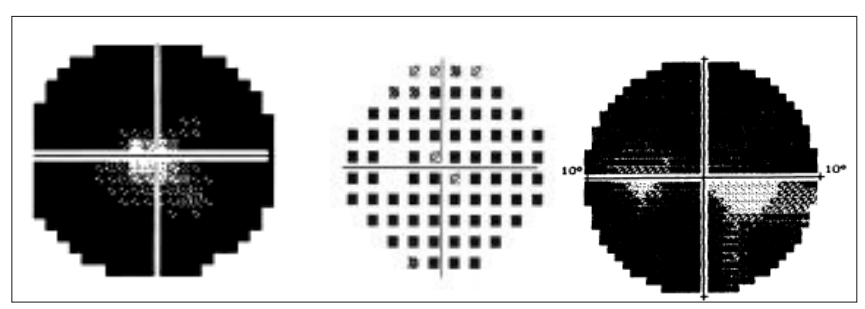

Şek. 5. Humprey 30-2 santral eşik testinde konsatrik daralma ve santral ve temporal adacık şeklinde alan defektleri

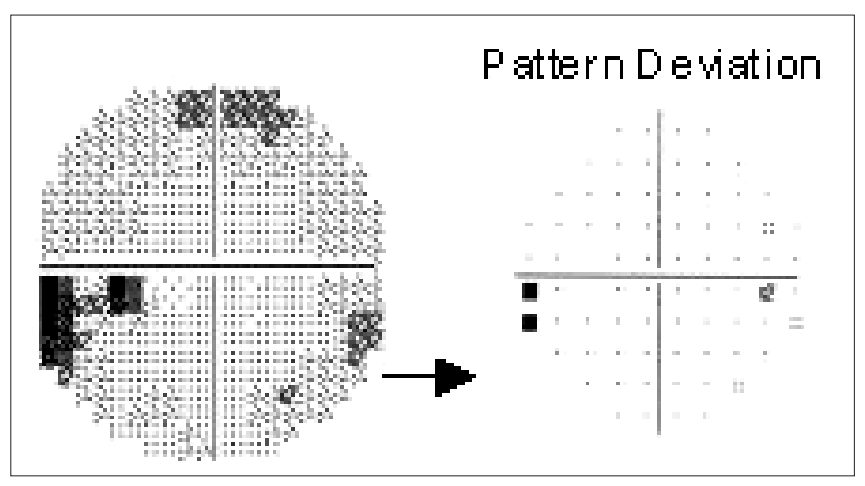

Şek. 6. Glokomlu bir hastada santral 30-2 eşik testinde "Temporal wedge" görünümü kaybı olur (Şek. 6). Bu defektler genellikle geç dönemde görülür.

\subsection{Glokomda erken ve geç dönem görme alanı de- fektleri}

Glokomun başlangıç ve geç dönemlerinde görülen alan defektleri farklılık gösterir. Bu nedenle alan defekleri glokomun erken ve geç döneminde görülen alan defektleri olarak iki başlık altında incelenebilir:

4.2.1. Glokomda erken dönem görme alanı defektleri Görme alanının her yerinde olabilir. En çok üst yarıda (\%60), nazal defektler şeklinde görülür. Sığ veya izole GA defektleridir ve glokom için karakteristiktir. Derin, fiksasyon noktasına uzanan defektler geç veya son evre glokom için karakteristikdir. Arter dal tıkanıkları, korioretinal skarlar, optik nörit; optik sinir başı drusenlerinde de lokalize defektler oluşabilir ekarte edilmelidir (Heijl ve Lundquist, 1984). Erken dönem görülen defektlerin tipleri şunlardır;

\section{a-Işık duyarlılığında jeneralize kayıplar}

Diffüz alan kayıplarıdır. Diffüz homojen sensitivite kayıpları erken glokom hasarı bulgusu değildir. Genellikle ileri evre glokomlarda görülür (Asman ve Heijl, 1994). Bununla

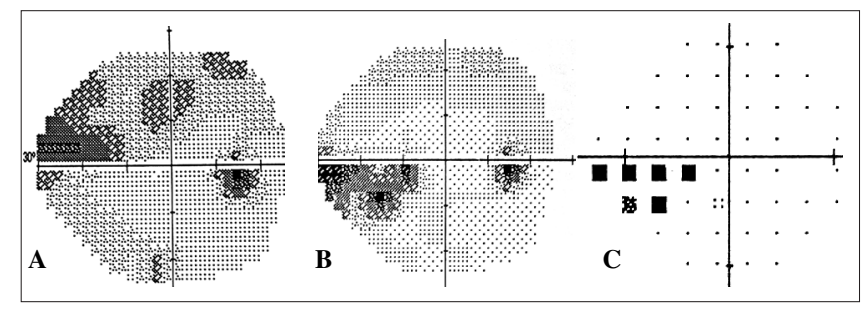

Şek. 7. Glokomlu bir hastada santral 30-2 eşik testinde, ANasal step ile birlikte parasantral skotom, B ve CNasal step görünümü.

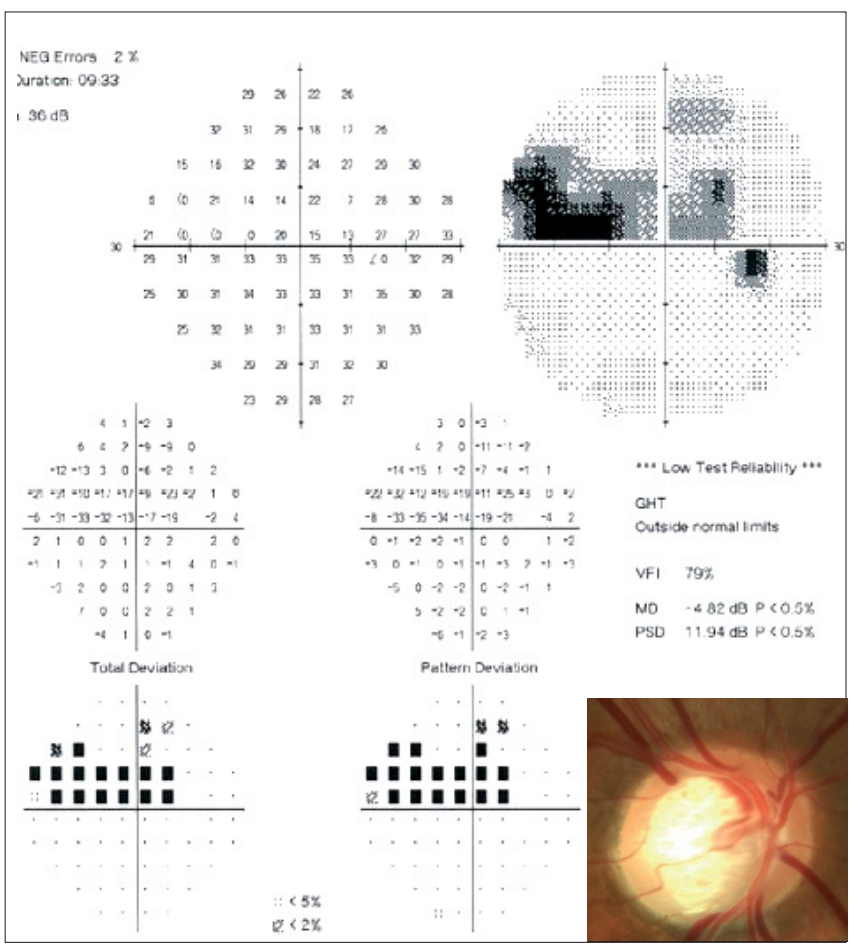

Şek. 8. Glokomlu bir hastada santral 30-2 eşik testinde arkuat defekt ve buna karşılık gelen optik diskte çentiklenme. 
birlikte bazen erken glokom bulgusu olabilir ve genellikle isopter kontraksiyonu olarak ifade edilir. Drance ve Lakowski (1981) asimetrik glokomu olup bir gözünde görme alanı defekti bulunan olgularda defektin olduğu gözde santral isopter kontraksiyonunun vakaların \%30 unda görüldüğünü bildirmişlerdir (Drance ve Lakowski, 1981) Hart ve Becker (1982) kontrol grubu ile karşılaştırdıkları çalışmalarında belirgin görme alanı defektleri oluşmadan önceki yıl boyunca isopter kontraksiyonu oluştuğunu bulmuşlardır.

Lokalize alan defekt gelişimi olan gözlerde, \%31 inde önce santral isopter kontraksiyonu, \%35,6 olguda önce kör nokta genişlemesi görüldüğünü tesbit etmişlerdir. Katarakt, miyosis ve refraksiyon kusurları varlığında da diffüz kayıplar olabilir, ekarte edilmelidir.

\section{b-Lokalize kayıplar}

Glokomatöz alan defektleri optik disk ve RSLT nın anatomik özellikleri ile açıklanır. Bu nedenle glokomatöz görme alanı defektleri çoğunlukla lokalizedir, horizontal meridyeni aşmaz, genellikle bjerrium alanı içinde kör noktanın nazalinden başlar ve çoğunlukla merkezi $30^{\circ}$ lik alanda tesbit edilir. RSLT nın arkuat şeklinde olması, erken lokalize kayıp şeklinde arkuat özellikte, ayna hayali görünümünde olmasına neden olur ve bu hastalığın bulgusudur. RSLT da aksonal demetler belli düzende seyreder, daha uzun aksonlar retinada daha derinde yer alır, bu nedenle lokalize defektlerde yalnız belli uzunluktaki liflerde etkilenme oluşur. Bu da ters yarı alanda parasantral skotom şeklinde gözlenir. Parasantral skotom $10^{\circ}$ lik alan içinde ortaya çıkan rölatif veya absolü defektlerdir. Erken dönemde kör nokta ile birleşik değildir. Kör nokta ile birleştiğinde "Siedel skotomu” ismini alır.

"Nasal step" ise, kısmi veya total RSLT lezyonlarında, temporal yarı alanda üst veya alt da, retinada temporal çizgiyi (raphe) geçmeyen alan kaybıdır (Şek. 7). Parasantral alan dışındaki periferik arkuat liflerin oluşturduğu defekttir. Glokomun erken bulgularından biridir. Glokomda retinanın alt ve üst yarısında sinir lifi harabiyeti her zaman simetrik seyretmez, bu lifler anatomik olarak horizontal meridyende birleşmedikleri için sinir lifi defektleri üst ve alt kadranın temporalinde basamak şeklinde defektler oluştururlar. Görme alanında nasal basamak olarak değerlendirilirler. Nasal step glokom olgularında en erken görülen görme kaybı bulgusu olabilir, fakat kesinlikle glokoma spesifik değildir. Herhangi bir optik nöropatide alt nasal kadranda depresyon papil ödem ve disk drusen de dahil, erken bulgu olarak gelişebilir (Wall ve ark., 1983). Bu nedenle optik diskde "cupping" ve "notching" varlığı araştırılmalıdır.

Arkuat veya Bjerium skotomu kör nokta ile birleşebilir ve bu optik diskde rim üzerinde lokalize bir hasarın bulgusudur, rimin tamamının etkilenmesi optik disk kenarında glokomatöz çentik oluşuna yol açar (Şek. 8). İzole parasantral skotomlar bjerrium alanı içinde kör noktadan başlayıp, makula çevresinden dolaşarak nasalde fiksasyon noktasının $5^{\circ}$ yakınına ilerleyip arkuat skotomları oluşturur.

\section{c-Temporal sektör defektleri}

Glokomda oluşabilecek nadir alan defektlerinden biridir. Glokom hastalarının \%5' inde görülür. Retinanın nasal bölgesindeki lifler geniş bir alanda yelpaze şeklinde direkt optik diske ulaştığı için, etkilenme genellikle nadirdir. Etkilenme oluştuğunda kör noktanın temporalinde sektör şeklinde defekt gelişir.

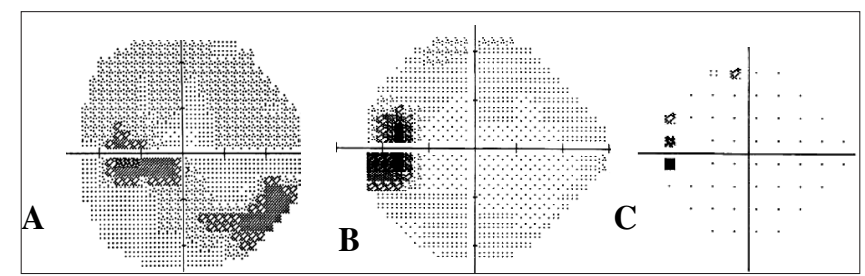

Şek. 9. Glokomlu bir hastada santral 30-2 eşik testinde, kör noktanın büyümesi(A-Arkuat skotom başlangıcı ve $\mathrm{B}$ ve $\mathrm{C}$-temporal wedge nedeniyle)

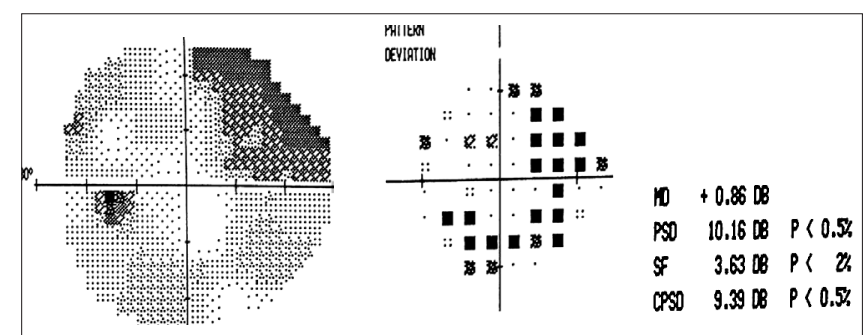

Şek. 10. Glokomlu bir hastada santral 30-2 eşik testindeki kısa süreli fluktasyonların gri skala görünümü ve global index değerleri.

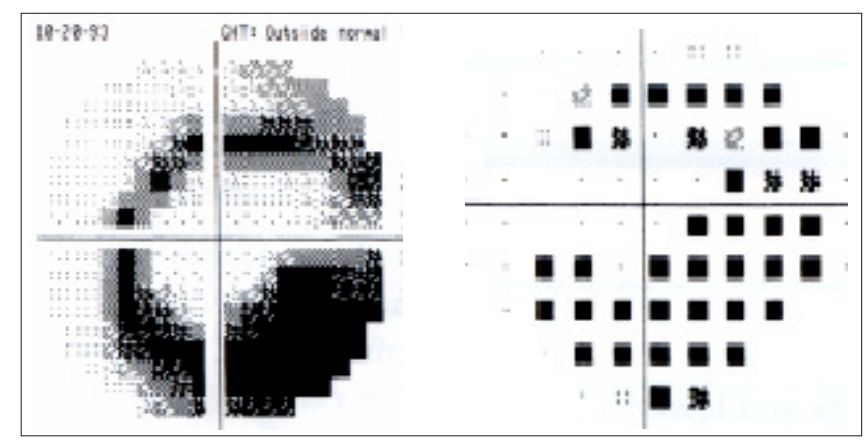

Şek. 11. İleri evre glokomu olan hastanın santral 30-2 eşik testinde "ring" skotom.

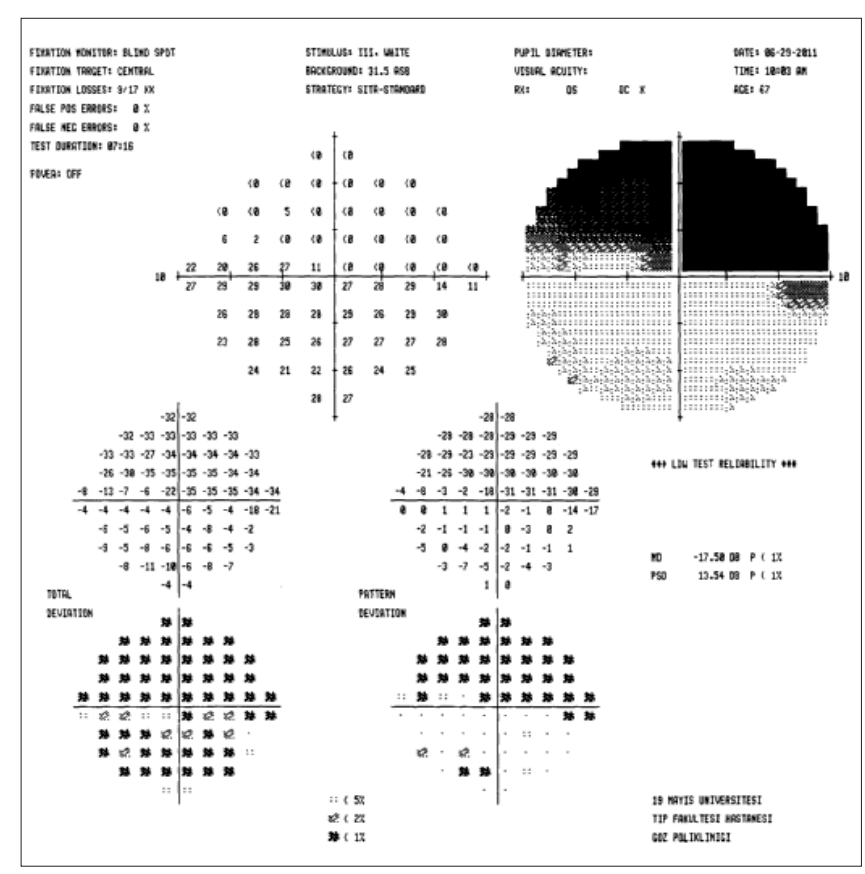

Şek. 12. İleri evre glokomu olan hastanın santral 10-2 eşik testinde yarı alan defekti. 
Temporal wedge defektler genellikle optik kiyazmanın etkilendiği infiltratif veya kompresif patolojilerde temporalde daha belirgin olarak görülür.

\section{d-Kör noktanın büyümesi}

Peripapiller sensitivite azalması ile belirgin hale gelir ve erken glokomun belirtisi olabilir (Şek. 9). Glokom için patogonomik değildir. Üç nedenle kör noktanın büyümesi mümkün:1-Nadir de olsa arkuat skotom bazen kör noktanın yakınında başlayabilir ve kör noktanın büyümesi gibi algılabilir, gerçek kör nokta büyümesi değildir. 2-Glokom hastalarında peripapiller atrofi, normal kişilere göre fazla görülür ve hastalığın seyri boyunca büyüyebilir. Peripapiller atrofiler genellikle stabildir ve patolojik değillerdir. 3- Kör noktaya yakın parasantral skotom varlığı.

\section{e- Anjioskotoma}

Uzun dal şeklinde kör noktanın alt ya da üstünde olabilir ve büyük retinal damarların gölgesinden oluşur. Erken glokomatöz alan defekti olarak oluşabilir, teknik olarak tesbit etmek zordur.

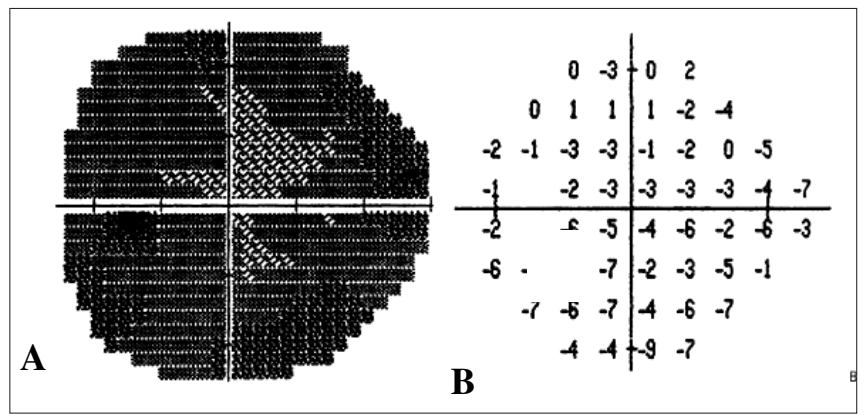

Şek. 13. İleri evre glokomu olan hastanın santral 30-2 eşik testinde A ve B generalize ve santral depresyon

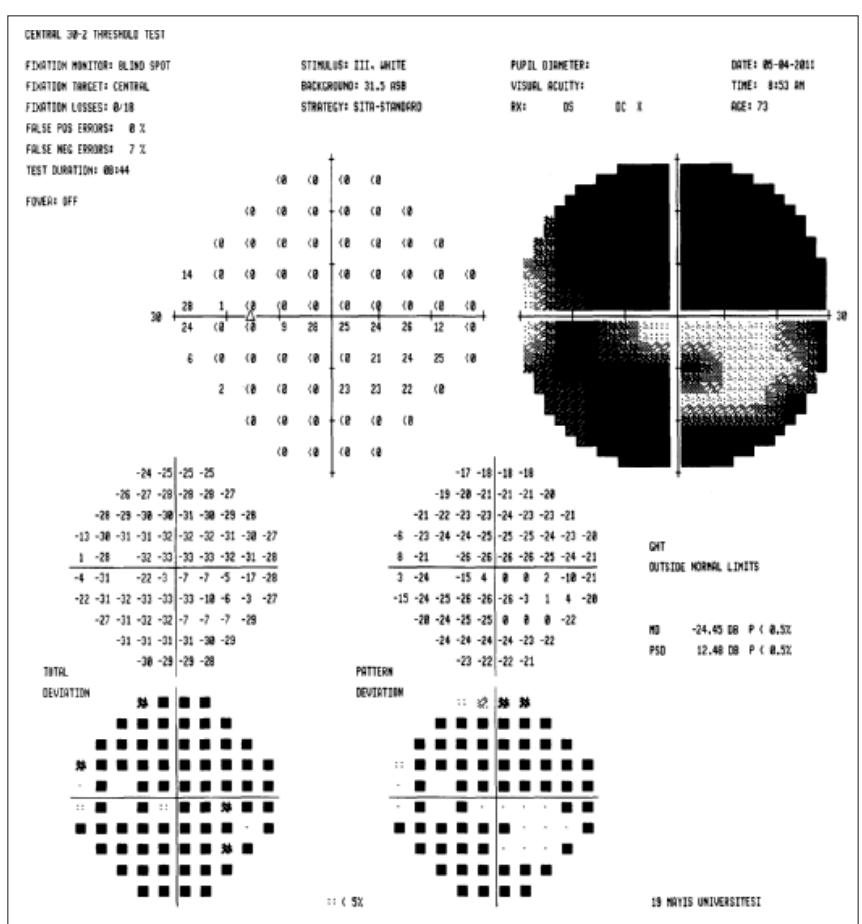

Şek. 14. İleri evre glokomu olan hastanın santral 30-2 eşik testinde, temporal ve santral adacık şeklinde görme alanı.

\section{f-Kısa süreli fluktuasyonlar}

Test içindeki hasta yanıtlarının değişkenliğidir (Şek. 10). Erken defekt bulgusu olabilir. Tekrarlanan görme alanı testlerinde fluktuasyonların hep aynı yerde olup olmadığına dikkat edilmelidir (Flammer ve ark., 1984). Glokomda tipik alan kayıpları, Bijerium alanında arkuat defektler, nasal step veya nazal wedge dir. Bu tipik kayıplar oluşmadan önce sıklıkla yıllar içinde perimetrik sensitivitede flüktasyonlar (oynamalar) görülür (Werner ve Drance, 1977).

Hart ve Becker (1982) yaptıkları çalışmada, başlangıç görme alanı defektlerinin \%54'ünün nasal step, \%41'inin parasantral veya arkuat skotom, \%30'nun arkuat kör nokta büyümesi, \%20'sinin izole arkuat skotom ve \% 3'ünün temporal defekt şeklinde olduğunu bildirmiştir. Werner ve Drance (1977) yaptıkları prospektif bir çalışmada ise, başlangıçta normal GA olan gözlerde ilk ortaya çıkan alan defektlerin \% 51 nasal step ile birlikte parasantral skotom, \%26 izole parasantral skotom, \%20 sadece nasal step olduğunu tesbit etmişlerdir.

\subsubsection{Glokomda ileri evre, geç dönem GA defektleri}

Glokomatöz alan defektleri doğal olarak glokomun ilerleyişi ile birlikte genişlemekte ve derinleşmektedir.

a-Ring skotom: Glokomun ileri evrelerinde alt ve üst yarı arkuat skotomları, birleşerek santral görmenin korunduğu çift arkuat veya halka (ring skotoma) skotomlarını oluştururlar (Şek. 11).

b-Hemifield defekt: Yarı görme alan kaybıdır (Şek. 12). Arkuat skotom arkuat alan dışında perifere ve santrale yay1lım göstererek alt ya da üst yarıyı içeren alan defektleri oluşur.

c-Konsatrik daralma: Periferik konsantrik daralmadır, tübüler görme nedenidir (Şek. 5).

d-Genel depresyon: Yaygın sensitivite kaybıdır (Şek. 13). Katarakt, miyozis ve refraksiyon kusuru varlığında da görülebilir. Glokomdan ayırt edilmesi gerekir.

e-Temporal adacık ve santral adacık şeklinde görme alan1: Son evrede en dirençli olan nasal ve papillamaküler liflerin kalan liflerinin oluşturduğu temporal ve küçük bir santral adacık kalır (Şek. 14).

\section{Glokom tiplerine göre alan defektleri}

Görme alanı defektleri erken ve geç dönemde genellikle glokom tiplerine göre değişiklik göstermez, fakat başlangıç defektleri bazı glokom tiplerinde farklı özellikler içerir.

\subsection{Normal tansiyonlu glokomda görme alanı deği- şiklikleri}

Göziçi basıncındaki değişiklikler görme alanı defektlerinin yapısını etkileyebilir. GİB nın yüksek seyrettiği kronik açık aç1lı glokomlarda lokalize defektlerden ziyade diffüz depresyon şeklinde alan kayıpları görülür. GİB nın 21 mmHg nın üzerine çıkmayan normal tansiyonlu glokomlarda (NTG) görme alanında defektler daha derin, daha keskin sınırlı ve fiksasyon noktasına yakın yerleşimlidir (Caprioli ve Spaeth, 1984; Araie, 1995). Başka bir çalışmada fokal defektlerde istatiksel olarak anlamlı olmayan derinlik farkı olduğu, fakat normal tansiyonlu glokomda alt yarı alanda daha fazla lokalize kayıpların olduğu gösterilmiş ve bu vasküler mekanizma ile açıklanmıştır (Zeiter ve ark., 1992). Takada ve ark., (1993) normal tansiyonlu glokomda (NTG) 5-10 derecelik üst santral görme alanında primer açık açılı glokoma (PAAG) göre 
daha fazla depresyon görüldüğünü bildirmiştir.

Eksfoliatif yüksek basınçlı glokom ile NTG görme alanı progresyon hızları arasındaki fark karşılaştıııldığında NTG da santral görme alanında daha fazla progresyon görülmekte, fakat progresyon hızı benzer bulunmuştur (Ahrlich ve ark., 2010).

\subsection{Akut basınç yükselmelerinde görme alanı değişik- likleri}

GİB nın ani yükselmesi akut açı kapanması glokomu gibi durumlarda genel depresyon, erken santral görme kaybı, arkuat skotom, kör noktanın büyümesi gibi farklı alan değişiklikleri bildirilmiştir. Atak sonrası kontrol altına alınan hastalarda bazen bunlar normale dönerken bazı hastalarda renkli görmede azalma, genel depresyon ve özellikle üst yarı alanda daralma kalıcı olabilmektedir. Değişiklikler okuler perfüzyon basıncına bağlı olarak geri dönüşümlü olabilir (Trible ve Anderson, 1997). Glokomda görme alanında tesbit edilen alan defektlerinin tümü kalıcı olmayabilir. GİB nın düșürülmesi ile defektlerde düzelme görülse bile uzun süreli takiplerde bu bölgelerde tekrar alan defektleri geri gelmektedir (Phelps, 1979).

\section{Sonuç}

Görme alanı kaybı hastanın yaşam kalitesini etkileyen bir durumdur. Karakteristik GA defekleri, optik sinir ve retina sinir lifi tabakasında görülebilir bir hasar oluştuğunda bile, glokom için en önemli tanı bulgusudur. Glokomatöz alan kayıpları santral görme alanında her yerde olabilir, fakat çoğunlukla nasalde ve özellikle üst yarıda görülür. Periferik retinada lezyon oluşumu sık değildir. Glokomatöz alan defektleri çoğunlukla periferal nasal step şeklinde, veya daha küçük üst veya altta arkuat sinir lifi demet bölgelerinde parasantral sko- tom şeklinde başlar. Bu, kısmi veya tam kör noktadan nasale horizontal meridyen boyunca uzanan arkuat skotom şeklinde genişler. Başlangıç glokomatöz alan defektleri vakaların çoğunda üst veya alt yarı alanda yer alır. Glaucoma hemifield test GHT horizontal yarı alanları karşılaştırmada, varsa asimetrik ayna hayali defektleri göstermede oldukça etkin bir testdir. Tam arkuat defekt geliştiğinde sıklıkla diğer yarı alanda da defektler oluşacaktır ve tüm nasal alanı tutabilir. Son evre glokomlarda sadece küçük santral adacık kalır ve temporalde küçük ikinci bir adacık kalır. Genellikle temporal adacık en son tutulur. Doğru değerlendirme için alan çıktısında gri scaladan çok olasılık haritasına bakmak gerekir. Patern deviasyon, daha çok lokalize alan kayıplarını değerlendirmede faydalıdır. Diffüz sensitivite kayıpları miyosis veya katarakt varlığını gösterir.

Glokomda oluşan GA defektlerinin başlangıçta görülme oranları şöyledir: Parasantral defektler \%41, Nasal step \%54, kör noktanın arkuat genişlemesi \%30, kör nokta ile birleşmeyen arkuat skotom $\% 90$, temporal wedge defekti $\% 3$ dür (Hart ve Becker 1982). Özellikle sığ ve izole defektler erken glokom için derin ve fiksasyon noktasına yakın defektler ise daha çok geç veya son evre glokom için karakteristiktir.

Genel olarak optik disk ve retina sinir lifi değişiklikleri, erken evre glokomlarda, görme alanı ise progresyonu daha iyi takip edebilmek için tedavi altındaki ileri evre glokomlarda daha çok faydalıdır. Glokom olgularında ilk test $\% 45$ olguda, popülasyon çalışmalarında $\% 59$, normal olgularda $\% 30$ güvenilir bulunmamıştır. Kesin tanı için GA testi en az dört kez tekrarlanmalıdır. Geniş defektlerde ve periferik defektlerde santrale göre, eşik duyarlılıkta değişkenlik fazla olduğu için dikkatli olunmalıdır (Katz ve Sommer, 1988).

\section{KAYNAKLAR}

Ahrlich, K.G., De Moraes, C.G., Teng, C.C., Prata, T.S., Tello, C., Ritch, R., Liebmann, J.M., 2010. Visual field progression differences between normal-tension and exfoliative high-tension glaucoma. Invest. Ophthalmol. Vis. Sci. 51, 1458-1463.

Anderson, D.R., Patella, V.M., 1999. Automated Static Perimetry. St Louise:Mosby. 237, 29-34

Araie, M., 1995. Pattern of visual field defects in normal-tension and high-tension glaucoma. Curr. Opin. Ophthalmol. 8, 36-45.

Asman, P., Heijl, A., 1994. Diffuse visual field loss and glaucoma. Acta. Ophthalmol. 72, 303-308.

Armaly, M.F., 1972. Selective perimetry for glaucomatous defects in ocular hypertension. Arch. Ophthalmol. 87, 518-524.

Balon, B.J., Echelman, D.A., Shields, M.B., Ollie, A.R., 1992. Peripheral visual field testing in glaucoma by automated kinetic perimetry with the Humphrey Field Analyzer. Arch. Ophthalmol. 110, 1730-1732.

Caprioli, J., Spaeth, G.L., 1984. Comparison of visual field defects in the low tension glaucomas with those in the high- tension glaucomas. Am. J. Ophthalmol. 97, 730-737.

Drance, S.M., Airaksinen, P.J., Price, M., Schulzer, M., Douglas, G.R., Tansley, B.W., 1986. The correlation of functional and structural measurements in glaucoma patients and normal subjects. Am. J. Ophthalmol. 102, 612-616.

Drance, S.M., 1969. The early visual field defects in glaucoma. Invest. Ophthalmol. 8, 84-91.

Drance, S.M., Lakowski, R., 1981. Early psychophysical disturbances in choronic open-angle glaucoma.In Transactions of the New Orleans Academy of Ophthalmology, St Louis,Mosby.

Flammer, J., Drance, S.M., Zulauf, M., 1984. Differantial light treshold.Short and long-term fluctuation in patients with glaucoma, normal controls, and patients with suspected glaucoma. Arch. Ophthalmol. 102, 704-706.

Gordon, M.O., Beiser, J.A., Brandt, J.D., Heuer, D.K., Higginbotham, E.J., Johnson, C.A., Keltner, J.L., Miller, J.P., Parrish, R.K., Wilson, M.R., Kass, M.A., 2002. The Ocular hypertension Treatment study:baseline factors that predict the onset of primary open-angle glaucoma. Arch. Ophthalmol. 120, 714-720.

Gramer, E., Gerlach, R., Krieglstein, G.K., Leydhecker, W., 1982.Topography of early glaucomatous visual field defects in computerized perimetry(in German). Klin. Monatsbl. Augenheilkd. 180, 515-523.

Harrington, D.O., 1965. The bjerrum scotoma. Am. J. Ophthalmol. 59, 646-656.

Hart, W.M., Becker, B., 1982. The onset and evaluation of glaucomatous visual field defects. Ophthalmol. 89, 268-271.

Heijl, A., Bengtsson, B., 1996. The effect of perimetric experience in patients with glaucoma. Arch. Ophthalmol. 114, $19-24$.

Heijl, A., 2000. The glaucomatous visual field.In:Glaucoma in the 21st century. Weinreb RN, Kitazawa Y, Krieglstein GK eds. Mosby İnternational Ltd., London. 35-42.

Heijl, A., Lindgren, G., Olsson, J., 1987. Normal variability of static perimetric treshold values across the central visual field. Arch. Ophthalmol. $105,1544-1549$.

Heijl, A., Lundqvist, L., 1984. The location of earliest glaucomataus visual defecets documented by automatic perimetry. Acta. Ophthal. 62 , 
658-664.

Katz, J., Sommer, A., 1988. Reliability indexes of automated perimetric tests. Arc. Ophthalmol. 106, 1252-1254.

Lachenmayer, B.J., Drance, S.M., Airaksinen, P.J., 1992. Diffuse field loss and diffuse retinal nerve-fiber loss in glaucoma. Ger. J. Ophthalmol. 1, 22-25.

Lau, L.I., Liu, C.J., Chou, J.C., Hsu, W.M., Liu, J.H., 2003. Pattern of viual field defects in chronic angle closure glaucoma with different disease severetiy. Ophthalmol. 110, 1890-1894.

Lynn, J.R., 1975.Correlation of pathogenesis, anatomy, and patterns of visual loss in glaucoma. In:Symposium on Glaucoma. St.Louise: Mosby. 151.

Mikelberg, F.S., Drance, S.M., 1996. Glaucomatous visual field defects.In:The Glaucomas, Glaucoma Therapy. Vol.1, Ritch R, Shields MB, Krupin T, eds. Mosby, St Louise. 523-537.

Phelps, C.D., Hayreh, S.S., Montague, P.R., 1984. Comparison of visual field defects in the low-tension glaucomas with those in the high-tension glaucomas. Am. J. Ophthalmol. 98, 823-825.

Phelps, C.D., 1979. Visual field defects in open angle glaucoma:Progression and regression. Doc. Ophthalmol. Proc. Series. 19, 187-196.

Takada, M., Araie, M., Suzuki, Y., Koseki, N., Yamagami, J., 1993. The central visual field defects in low-tension glaucoma. A comparison of the central visual field defects in low-tension glaucoma with those in primary open angle glaucoma. Nippon Ganka Gakkai Zasshi. 97, 13201324.

Trible, J.R., Anderson, D.R., 1997. Factors associated with intraocular pressure-induced acute visual field depression. Arch. Ophthalmol. 115, 15231527.

Quigley, H.A., Dunkelberger, G.R., Gren, W.R., 1989. Retinal ganglion cell atrophy correlated with automated perimetry in human eyes with glaucoma. Am. J.Ophthalmol. 107, 453-464.

Quigley, H.A., Katz, J., Derick, R.J., Gilbert, D., Sommer, A., 2003. An evaluation of optic disc and nevre fiber layer examination in monitoring progression of early glaucoma damage. Ophthalmol. 99, 19-28.

Wall, M., Hart, W.M.J., Burde, R.M., 1983. Visual field defects in idiopathic intracranial hypertension(pseudotumor cerebri). Am. J. Ophthalmol. 96, 654-669.

Werner, E.B., Drance, S.M., 1977. Early visual field disturbances in glaucoma. Arch. Ophthalmol. 95, 1173.

Werner, E.B., Drance, S.M.,1977. Early visual field disturbances in glaucoma. Arch. Ophthalmol. 95, 1173-1175.

Zeiter, J.H., Shin, D.H., Juzych, M.S., Jarvi, T.S., Spoor, T,C., Zwas, F., 1992.Visual field defects in patients with normal-tension glaucoma and patients with high-tension glaucoma. Am. J. Ophthalmol. 114, 758-763. 